\title{
« Religiöse Bücher, Grenzen und Identitäten »
}

«Livres, frontières et identités religieuses »

\section{Juliette Guilbaud et Andreas Ohlemacher}

\section{OpenEdition}

\section{Journals}

Édition électronique

URL : http://journals.openedition.org/ifha/119

DOI : 10.4000/ifha. 119

ISSN : 2198-8943

\section{Éditeur}

IFRA - Institut franco-allemand (sciences historiques et sociales)

\section{Édition imprimée}

Date de publication : 6 février 2011

Pagination : 28-31

ISSN : 2190-0078

\section{Référence électronique}

Juliette Guilbaud et Andreas Ohlemacher, « "Religiöse Bücher, Grenzen und Identitäten » », Revue de I'IFHA [En ligne], 3 | 2011, mis en ligne le 01 octobre 2012, consulté le 22 avril 2019. URL : http:// journals.openedition.org/ifha/119; DOI : 10.4000/ifha.119

Ce document a été généré automatiquement le 22 avril 2019.

(C)IFHA 


\section{«Religiöse Bücher, Grenzen und Identitäten »}

«Livres, frontières et identités religieuses »

Juliette Guilbaud et Andreas Ohlemacher

\section{NOTE DE L'ÉDITEUR}

Colloque international, Göttingen, 12-13 novembre 2010

En novembre 2010 s'est tenu le colloque du projet «Buchpraxis. Les usages religieux du livre à l'époque moderne. Une comparaison transculturelle et interconfessionnelle (France-Empire) ", colloque coorganisé par le Centre de recherches interdisciplinaires sur l'Allemagne (UMR 8131, EHESS-CNRS, Paris) et l'université de Göttingen, dans les locaux du Lichtenberg-Kolleg de Göttingen, avec le soutien financier de l'IFHA. Ce colloque venait clore un programme de recherche débuté en 2008, et cofinancé par l'Agence nationale de la recherche et la Deutsche Forschungsgemeinschaft. Pour l'équipe franco-helvéticoallemande du projet, constituée d'une quinzaine de spécialistes historiens, littéraires, théologiens et philosophes, entourés eux-mêmes pour cette rencontre d'une dizaine de chercheurs invités issus de ces disciplines, l'objectif était d'éclairer le rôle de la pratique du livre religieux - mais aussi de la pratique religieuse de livres a priori non religieux dans la formation des identités religieuses, voire confessionnelles.

Cette réunion venait couronner une série d'ateliers organisés depuis deux ans et demi : en 2008 à Wolfenbüttel («Cantiques, psautiers, livres de chant: pratiques religieuses à l'époque moderne »), en 2009 à Paris puis à Gotha («Canaux et réseaux de diffusion des livres religieux en France et dans l'Empire à l'époque moderne [XVIe-XVIIIe siècle] » et «En quête de l'auteur de livres religieux ») et en 2010 à Nancy (« Modes de lecture, appropriations »). La rencontre de Göttingen s'est déroulée comme les précédentes, à savoir sous la forme de courtes communications (une vingtaine de minutes) en français ou en allemand selon l'intervenant(e), afin de privilégier le temps de la discussion 
collective. Le programme du colloque était organisé en trois sections, "Identités individuelles et collectives » (I), "Pratiques du livre et interférences confessionnelles » (II), « Usages transculturels et interconfessionnels des textes » (III). Il se complétait d'une conférence publique solennelle de KASPAR VON GREYERZ (Bâle), prononcée au soir de la première journée devant un public nombreux et introduite avec brio par Thomas Kaufmann.

Susanne LACHENICHT (Bayreuth) ouvrit le bal pour la première section, avec une intervention sur «Buch- und Publikationspraktiken der Réfugiés in der Gelehrtenrepublik und nationale Identitäten ». Dans cet exposé, elle se penchait notamment sur le rôle de la presse dans la cohésion des différentes communautés de la diaspora réformée après la Révocation. Christophe DuHAMELLE (Paris) s'interrogeait ensuite sur les propositions de calendriers alternatifs dans l'Empire et posait la question suivante: "Les traités protestants sur le calendrier sont-ils des livres religieux? (Saint-Empire, XVIe-XVIIIe siècle). » De façon caractéristique, ces traités n'avaient de cesse de se présenter comme scientifiques et non comme proprement théologiques. Pour autant, la volonté d'affirmer sa distinction, autrement dit la logique du confessionnel, transformait ces livres scientifiques pour ainsi dire en livres religieux. Ulrike GLEIXNER (Wolfenbüttel/ Berlin), en prenant pour exemple le piétisme wurtembergeois, montra comment pouvait se construire et se révéler une identité religieuse spécifique, différente de la piété populaire, dans des textes mêlant éléments autobiographiques de l'auteur et réemplois de stéréotypes piochés dans d'autres biographies ("Wie aus dem Tagebuch eine fromme Biographie wird. Textkonversionen im Pietismus »). Gaël RIDEAU (Orléans) se pencha pour sa part sur « Les usages du livre dans les querelles religieuses en France au XVIIIe siècle », en particulier dans l'affrontement entre jansénistes et jésuites à travers leurs périodiques respectifs - les Nouvelles ecclésiastiques publiées par les premiers, et le Supplément aux Nouvelles ecclésiastiques des seconds. Il montra comment, dans ce contexte, le livre apparaît comme un marqueur identitaire selon l'usage qui en est prôné.

Premier orateur de la deuxième section, Laurent JALABERT (Nancy II) avait choisi de se pencher sur «Les livres religieux dans les campagnes pluriconfessionnelles au XVIIIe siècle ", déplorant d'emblée la faible quantité de sources disponibles pour mener à bien une étude quantitative représentative. Il s'attacha cependant à éclairer les différents modes d'accès au livre offerts aux fidèles, la réception des ouvrages, le jugement des ecclésiastiques sur l'utilisation des volumes (utilisation qu'ils s'efforçaient d'ailleurs d'orienter), avant de conclure au rôle semble-t-il limité des livres religieux dans la construction d'une identité confessionnelle dans la Lorraine du XVIIIe siècle. Martin sCHEUTZ (Vienne) s'intéressait quant à lui aux multiples sources d'approvisionnement et aux différents usages des livres religieux chez les cryptoprotestants autrichiens du XVIIIe siècle, soucieux d'affirmer leur identité ("Verschenkte und versteckte Bücher bei den österreichischen Geheimprotestanten »). Didier BoIsson explora ensuite les récits de conversion catholiques et protestants dans la France de Louis XIV après la révocation de l'édit de Nantes, récits au miroir desquels il fit ressortir points communs et différences entre catholiques et protestants français dans cet exercice spécifique d'écriture : c'était pour tous une rupture, du point de vue non seulement spirituel, mais aussi souvent social et professionnel; et si les lectures des convertis catholiques et protestants étaient globalement les mêmes, leur interprétation était bien différente. En revanche, là où le désir d'intégration dans la nouvelle communauté est manifestement l'objectif principal des récits protestants, les textes catholiques sont largement inspirés par une volonté 
prosélyte. En point d'orgue de cette première journée, la présentation de Xenia voN TIPPELSKIRCH (Bochum), "Die Bücher der "Chrétiens sans Église": Versuche konfessioneller Verortung von Aussenseitern", revêtait un caractère presque méthodologique. Elle s'appuyait sur les travaux de Leszek Kołakowski, vantant la richesse d'une approche du discours identitaire qui se concentrerait non plus sur les courants relevant de l'orthodoxie, mais bien sur ces chrétiens marginaux, plus ou moins radicaux.

Pour débuter la seconde journée et la troisième séquence du colloque, Anne CONRAD (Sarrebruck) apporta un regard neuf sur les écrits de Friedrich Spee et de Hermann Busenbaum («Wie konfessionalistisch war jesuitische Literatur?»). Les textes de ces deux auteurs pour les membres des congrégations féminines révèlent en effet une certaine ouverture théologique et une argumentation qui assuraient une possible réception et influence de ces ouvrages aussi bien chez les catholiques que chez les protestantes. Véronique FERRER (Bordeaux III), dans sa contribution intitulée « Le livre de piété réformé francophone aux XVIe et XVIIe siècles: affirmation identitaire et échanges interconfessionnels", proposait pour sa part une analyse littéraire des distinctions, réemplois et interférences entre catholiques et réformés français. Ces usages transculturels semblent varier au rythme des contextes (temps de persécution, pacifications), mais reflètent toujours l'ambition d'affirmer une identité religieuse spécifique. Marianne CARBONNIER-BURKARD (Paris) présenta les fruits d'une enquête passionnante, ou comment elle suivit la piste des Precationes christianae, un recueil de prières du réformateur Capiton ( "Comment déconfessionnaliser un recueil de prières en France aux XVIe et XVIIe siècles?»). Par le jeu de transformations, d'additions et autres maquillages successifs, divers et variés, l'ouvrage fut reçu, utilisé et imité bien en dehors de la sphère protestante, jusqu'à sa publication sous le titre Thrésor de prières, dans une version quasiment "catholique »- ou ayant du moins toutes les apparences de la catholicité pour échapper à la censure. Sebastian KÜHN (Berlin) s'intéressait ensuite aux écrits du for privé, en particulier à ceux de Charlotte-Louise comtesse de Schwerin, pour souligner la diversité des lectures de cette dernière avant, pendant et après sa conversion, ainsi que leur réemploi (" “Comment, vous lisez des livres catholiques?” $\mathrm{Zu}$ den Lektürepraktiken einer Konvertitin »). Pour finir, Elisabeth ROTHMUND (Paris Est-Créteil) attira l'attention des participants sur «Un objet-livre singulier : la première traduction allemande des Sonnets chrétiens de Laurent Drelincourt, Stockholm, $1679 »$. Elle montra comment un texte réformé fut «importé » avec succès dans un contexte strictement luthérien.

Pour clore ces deux journées, six des membres de l'équipe du projet « Buchpraxis » avaient été invités à préparer à l'avance une très courte intervention (environ cinq minutes) résumant, de l'avis de chacun - plutôt que les stricts points forts et faiblesses du colloque et de l'ensemble du projet depuis 2008 - les développements constatés qui n'avaient pas été nécessairement attendus au début du projet, les questions surgies au cours de son évolution, ainsi que les pistes encore à explorer sur la pratique (religieuse ou non) de livres (religieux ou non). Ces six prises de position furent elles-mêmes commentées par Kaspar VON GREYERZ et l'occasion d'une discussion finale prospective. 